\title{
Patterns of ventricular contraction in patients with conduction abnormality studied by radionuclide angiocardiography
}

\author{
S R UNDERWOOD, S WALTON, P J LAMING, P J ELL, R W EMANUEL, R H SWANTON \\ From the Department of Cardiology and Institute of Nuclear Medicine, Middlesex Hospital and Medical School, \\ London
}

SUMMARY The phase image generated by radionuclide angiocardiography illustrates the regional timing of ventricular wall motion. In this study the phase image was used to investigate the patterns of ventricular contraction in 103 subjects with either normal hearts or a conduction abnormality. In 38 normal subjects the right ventricle contracted on average $7 \mathrm{~ms}$ after the left, and the last region to contract was the right ventricular outflow tract. In 15 subjects with left bundle branch block the left ventricle contracted $69 \mathrm{~ms}$ after the right, contraction spreading from the septum to the lateral wall. In 12 subjects with right bundle branch block right ventricular contraction occurred $54 \mathrm{~ms}$ after the left. In 11 subjects with right bundle branch block and left anterior fascicular block both right and left ventricular contraction were delayed, the right more so than the left. In three of five subjects with the Wolff-Parkinson-White syndrome and four with frequent ventricular extrasystoles areas of early contraction corresponded to areas of early depolarisation.

It is concluded that ventricular contraction can be studied non-invasively and follows a pattern to be expected from the pattern of electrical depolarisation.

Radionuclide angiocardiography is now firmly established in the non-invasive assessment of ventricular function. Traditionally, measurement of wall motion has been used as an index of regional contraction, but the recently introduced Fourier phase and amplitude images ${ }^{1-4}$ circumvent the problem of edge detection and provide a more complete description of wall motion. Fourier analysis quantifies the timing and magnitude of the cyclical changes in radioactive counts for each display element of the ventriculogram, and the phase and amplitude images so generated indicate the timing and magnitude of regional ventricular wall motion.

The purpose of this study was to use the phase image to investigate the timing and synchronisation of left and right ventricular contraction in a variety of conduction disorders including left and right bundle branch blocks, left anterior fascicular block, the Wolff-Parkinson-White syndrome, endocardial pacing, and ventricular extrasystoles.

Requests for reprints to Dr S R Underwood, Department of Cardiology, The Middlesex Hospital, Mortimer Street, London W1N 8AA.

Accepted for publication 13 December 1983

\section{Patients and methods}

One hundred and three subjects were studied at rest by electrocardiogram gated equilibrium radionuclide angiocardiography. Sixty-five had electrocardiographic evidence of a conduction abnormality (Table), and the phase image was used to compare the timing of contraction in these subjects with that in the 38 whom electrical conduction was normal. All subjects had a normal ejection fraction and amplitude image for the ventricle with abnormal conduction, and the extent of ventricular contraction was therefore normal.

\section{RADIONUCLIDE STUDIES}

Electrocardiogram gated equilibrium radionuclide ventriculography was carried out as previously described.$^{5-8}$ Briefly, after in vivo erythrocyte labelling with $740 \mathrm{MBq}(20 \mathrm{mCi})$ of technetium-99m sodium pertechnetate, a 16 frame representative cine cycle was acquired in a modified left anterior oblique projection using either a General Electric IGE400T or a General Electric Portacamera IIC gammacamera. Image acquisition and subsequent analysis were per- 
Table Conduction abnormalities and diagnosis in 103 patients studied

\begin{tabular}{|c|c|c|c|}
\hline Abnormality & No of subjects & Diagnosis & No of subjects \\
\hline None & 38 & Normal & \\
\hline Left bundle branch block & 15 & $\begin{array}{l}\text { Coronary artery disease } \\
\text { Conduction disease } \\
\text { Aortic valve disease } \\
\text { Mitral valve disease }\end{array}$ & $\begin{array}{l}8 \\
4 \\
2 \\
1\end{array}$ \\
\hline Right bundle branch block & 12 & $\begin{array}{l}\text { Coronary artery disease } \\
\text { Conduction disease } \\
\text { Aortic valve disease } \\
\text { Cardiomyopathy }\end{array}$ & $\begin{array}{l}6 \\
4 \\
1 \\
1\end{array}$ \\
\hline $\begin{array}{l}\text { Right bundle branch block and left } \\
\text { anterior fascicular block }\end{array}$ & 11 & $\begin{array}{l}\text { Coronary artery disease } \\
\text { Conduction disease } \\
\text { Malignant pericarditis }\end{array}$ & $\begin{array}{l}6 \\
4 \\
1\end{array}$ \\
\hline Pacemaker & 18 & $\left\{\begin{array}{l}\text { Conduction disease } \\
\text { Coronary artery disease }\end{array}\right.$ & $\begin{array}{r}13 \\
5\end{array}$ \\
\hline Pre-excitation & 5 & Wolff-Parkinson-White & 5 \\
\hline Ventricular extrasystoles & 4 & $\left\{\begin{array}{l}\text { Coronary artery disease } \\
\text { Conduction disease } \\
\text { Mitral valve disease }\end{array}\right.$ & $\begin{array}{l}2 \\
1 \\
1\end{array}$ \\
\hline
\end{tabular}

formed by an Informatek Simis III computer using standard software. Fourier phase and amplitude images were generated and, together with the end diastolic and end systolic images, were used to assign regions of interest manually for the left and right ventricles. The left ventricular region of interest was divided into eight overlapping quadrantic regions each rotated from the next by $45^{\circ}$, the centre of rotation being the counts weighted centre of gravity of the left ventricular end diastolic image. These eight regions thus approximate to different segments of the left
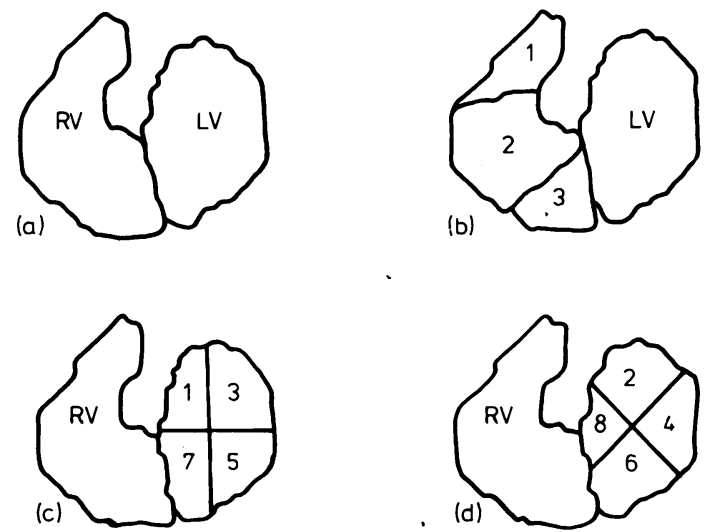

Fig. 1 (a) Left and right ventricular regions of interest. Approximate anatomical correspondence: (b) right ventricle (RV)-1, outflow tract; 2, body; 3, septum and apex; (c) and (d) left ventricle (LV)-1, proximal septum and base; 2, base; 3 to 5 , proximal to distal lateral wall; 6, apex; 7 to 8, distal to proximal septum. ventricular wall from proximal septum to base to posterolateral wall to apex to distal septum. The right ventricular region of interest was divided into three segments approximating to the outflow tract, body, and apex (Fig. 1).

\section{STATISTICAL METHODS}

Student's $t$ test was used as a test of statistical significance since mean left and right ventricular phase were normally distributed in the normal subjects.

\section{Results}

\section{NORMAL HEARTS}

Fig. 2 shows the mean global and regional phase values in the 38 subjects with normal conduction. The values are compared with those in the subjects with left bundle branch block (Fig. 2a), right bundle branch block (Fig. 2b), right bundle branch block with left anterior fascicular block (Fig. 2c), and right ventricular endocardial pacemakers (Fig. 2d). In the normal subjects the mean left ventricular phase was $135^{\circ}\left(\mathrm{SD} \pm 14^{\circ}\right)$ with the mean right ventricular phase $3^{\circ}$ higher. Within the right ventricle the outflow tract phase was $6^{\circ}$ higher than at the apex, whereas there was little variation within the left ventricle. None of these differences, however, achieved statistical significance. Fig. 3a shows a normal phase image.

\section{CONDUCTION ABNORMALITIES \\ Left bundle branch block}

In the subjects with left bundle branch block (Fig. 2a), the left ventricular phase was $29^{\circ}$ higher than the right ventricular phase $(p<0.001)$ and $35^{\circ}$ higher than 

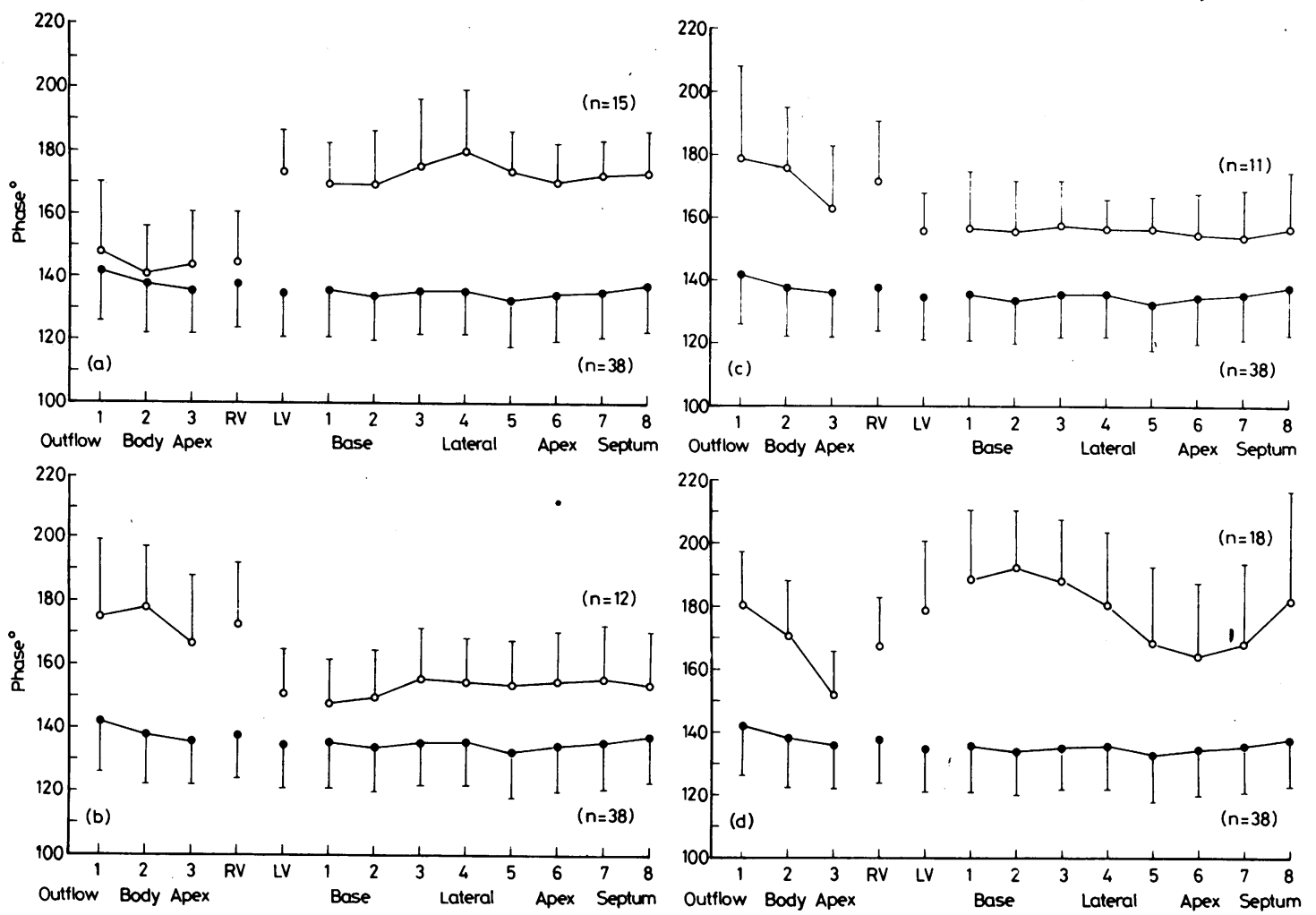

Fig. 2 Phase values (mean $\pm S D$ ) in normal subjects $(O)$ and $(a)$ those with left bundle branch block $(O),(b)$ those with right bundle branch block $(O),(c)$ those with right bundle and left anterior fasicular block $(O)$, and $(d)$ paced patients $(O)$.

in the normal subjects $(p<0.001)$. The right ventricular phase was not significantly different from normal. Within the left ventricle the highest phase values were seen in segment 4 (the posterolateral wall), and, although the differences were not statistically significant, in some individual patients the trend was pronounced, with lower phase values at the septum and progressively higher values spreading from this point (Fig. 3b).

Right bundle branch block

In right bundle branch block (Fig. 2b) the right ventricular phase was $35^{\circ}$ higher than in the normal subjects $(p<0.001)$ and $25^{\circ}$ higher than the mean left ventricular phase $(p<0.001)$. Within the right ventricle, the phase of the outflow tract and body were highest, but the differences were not statistically significant. Fig. 3c shows a typical phase image. It is of note that left ventricular phase was $13^{\circ}$ higher than in the normal subjects $(p<0.01)$, but since eight of these 12 subjects had disease which might be expected to affect the left ventricle this increase is not surprising even with normal left ventricular conduction.
Right bundle branch and left anterior fascicular block In combined right bundle branch block and left anterior fascicular block (Fig. 2c) both the right and left ventricular phases were higher than normal $(p<0.001)$, although the left ventricular phase was not as high as in complete left bundle branch block. In addition the right ventricular phase was higher than the left $(p<0.05)$. The right ventricular outflow tract had the highest values, but there was no variation within the left ventricle (Fig. 3d).

\section{Pacemaker}

In the patients with right ventricular endocardial pacemakers (Fig. 2d), both the right and left ventricular phases were higher than normal $(p<0.001)$, and, although the left ventricular phase was higher than the right, the difference was not statistically significant. The major feature, however, was that within each ventricle there was a large variation in phase with lowest values at the site of the pacing wire and also lower values at the left ventricular apex. The variation within each ventricle did achieve statistical significance $(p<0 \cdot 001)$. Fig. 3e shows a typical paced phase image. 
(a)
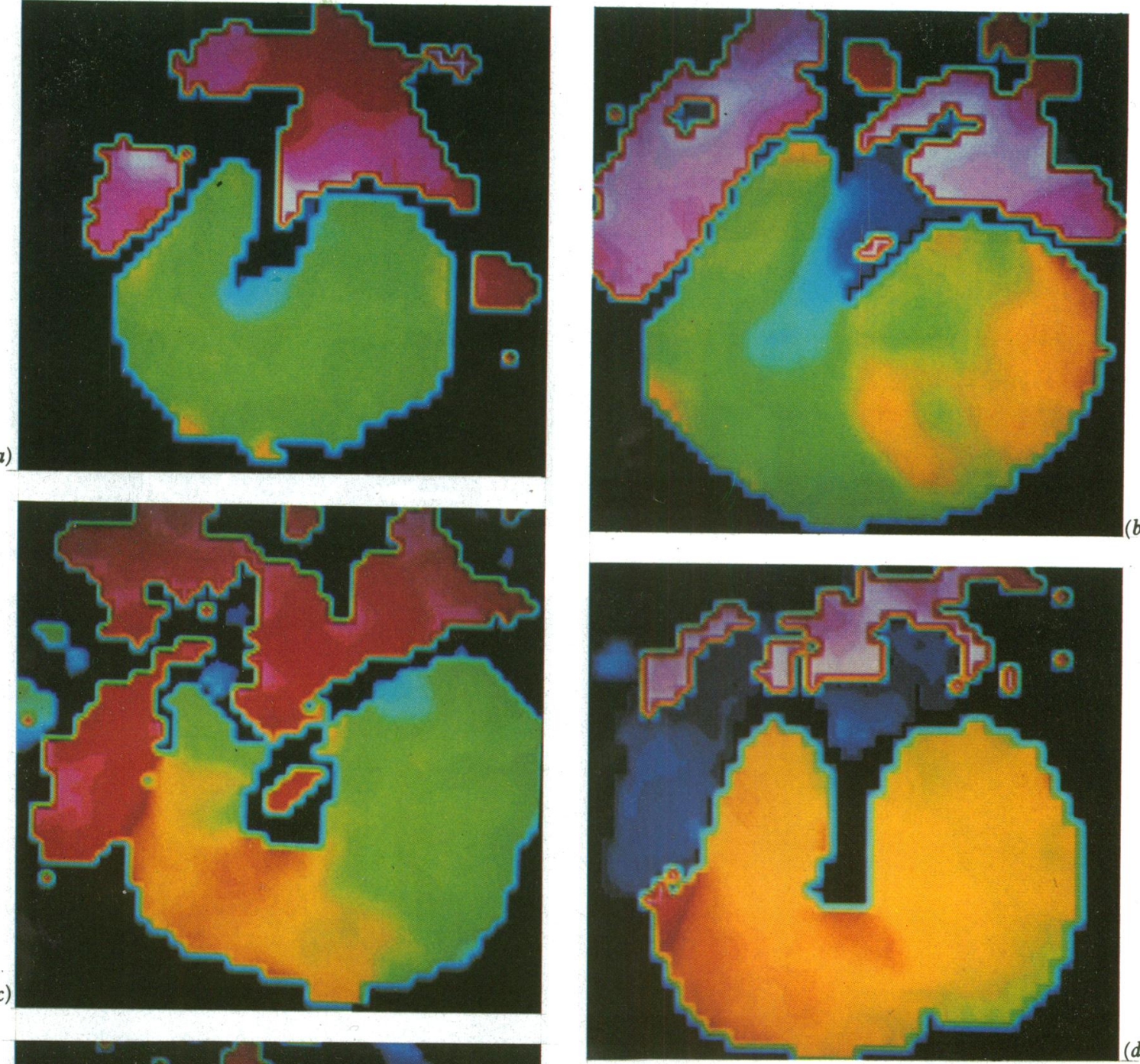

(d)

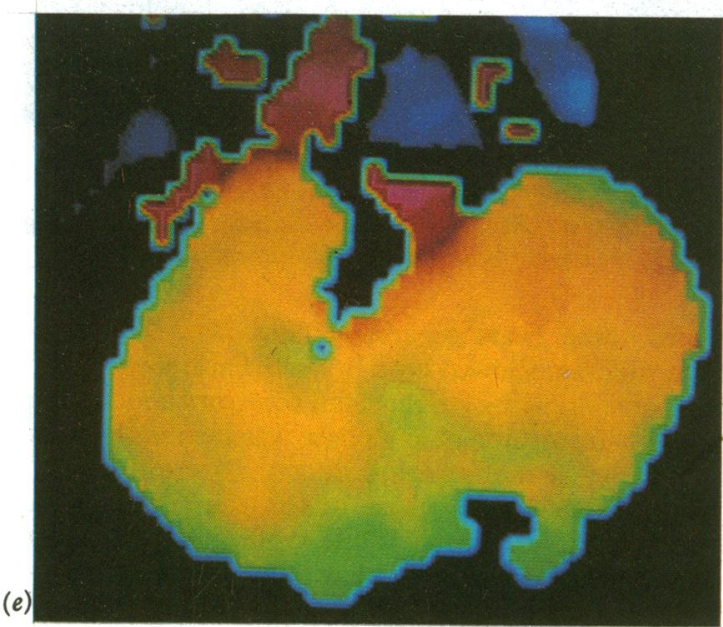

Fig. 3 (a) Normal phase image: normal ventricular phase values appear green, abnormal low values indicating early contraction blue, and abnormal high values indicating late contraction yellow and red; atrial and great vessel phase appear red, purple, and white. (b) Phase image in left bundle branch block: the left ventricle appears mainly yellow because of delayed contraction. The last region to contract is the anterolateral wall shown in orange. The right ventricle contracts normally (green). (c) Phase image in right bundle branch block: the body and apex of the right ventricle appear yellow and orange. The left ventricle contracts normally (green). (d) Phase image in right bundle branch block and left anterior fascicular block: both ventricles contract late, the right (orange) more so than the left (yellow). (e) Paced phase image: earliest contraction (green) is at the right ventricular apex, and contraction is progressively delayed spreading from this point. 

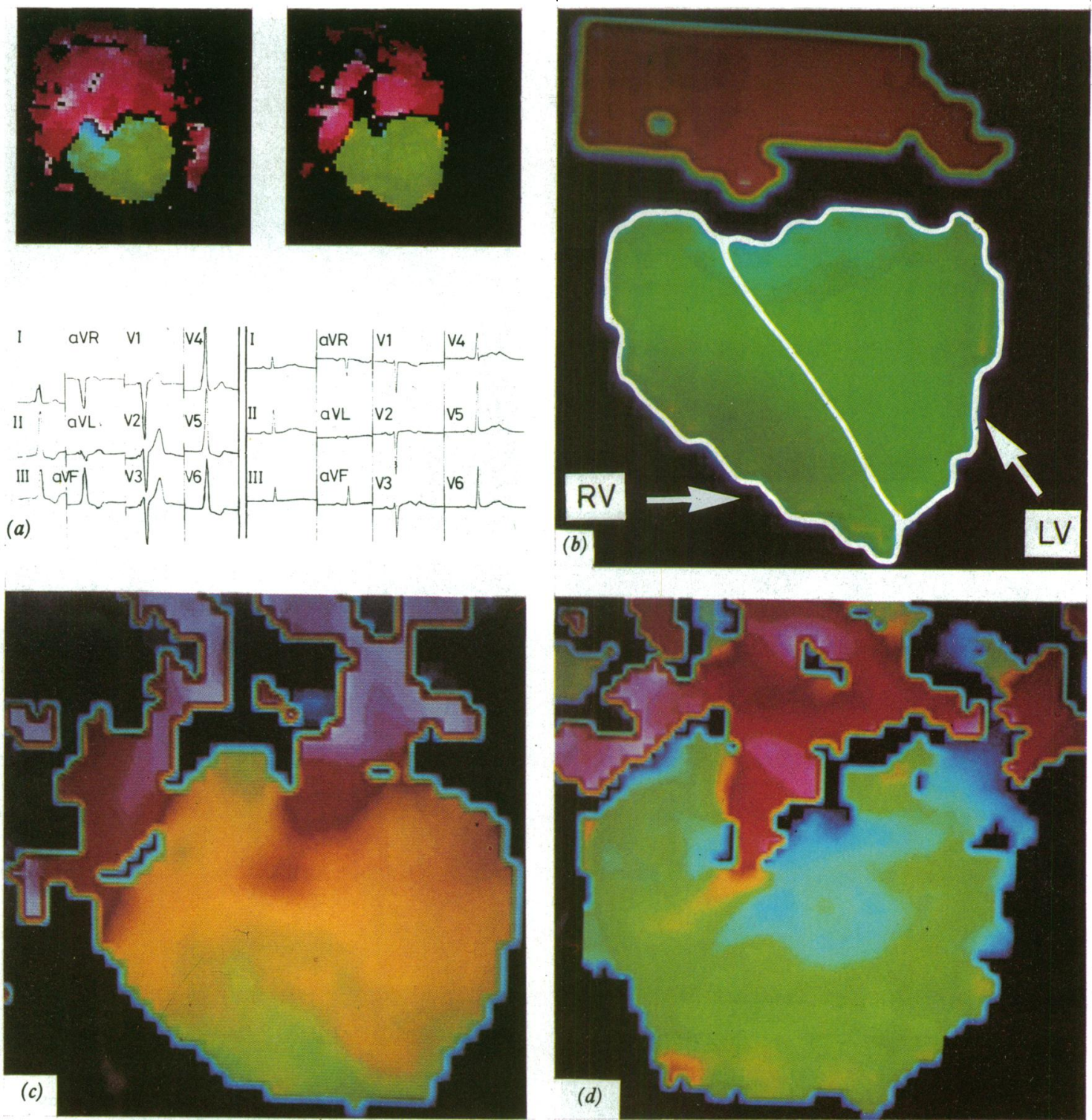

Fig. 4 (a) Wolff-Parkinson-White syndrome type B; normally conducted impulses (right) have a normal phase image; pre-excited impulses (left) show early contraction (blue) at the base of the right ventricle. (b) Wolff-Parkinson-White syndrome type A: early contraction (blue) at the left ventricular base. Left (LV) and right $(R V)$ ventricular regions of interest are shown. (c) and (d) Pacing with frequent lefi ventricular extrasystoles: paced beats (c), exitrasystoles (d), the ectopic focus is at the lefi ventricular base (blue).

\section{Wolff-Parkinson-White}

Five subjects with pre-excitation due to the WolffParkinson-White syndrome were studied, and in three of them areas of low phase were seen in the pre-excited area of the ventricle. In a fourth a small area of low phase was seen, but its significance was uncertain. One subject had alternating pre-excited and normally conducted beats, and it was possible to record these beats separately (Fig. 4a). The electrocardiogram showed type B Wolff-Parkinson-White syndrome implying a right sided accessory conducting bundle, and an area of low phase was seen in the high right ventricle and septal wall.

Fig. 4b shows the phase image of a subject with type A Wolff-Parkinson-White syndrome, with a left sided accessory bundle and low phase in the high sep- 
tum and base of the left ventricle.

\section{Ventricular extrasystoles}

Four subjects had frequent ventricular extrasystoles, and it was possible to produce a phase image from the extrasystoles alone. In all four, areas of low phase were seen corresponding to the electrocardiogram localisation of the site of the ectopic focus. One of these subjects was paced from the right ventricle but had frequent left ventricular extrasystoles. The difference in the phase images (Fig. $4 \mathrm{c}$ and d) is clear.

\section{Discussion}

Previous studies of the sequence of electrical activation $^{9-11}$ and mechanical contraction ${ }^{12} 13$ of the heart have shown that the two follow the same pattern, and it is a reasonable assumption that the delays in contraction shown in this study are a direct consequence of the delays in activation. Durrer et al showed that in the normal isolated human heart right ventricular endocardial activation begins $5-10 \mathrm{~ms}$ after left. ${ }^{10}$ The $3^{\circ}$ phase delay of the normal right ventricle shown in this study corresponds to a $7 \mathrm{~ms}$ delay at a rate of 70 beats/minute and so is compatible with the delay in activation. In left bundle branch block Wyndham et al showed a $54 \mathrm{~ms}$ delay in left ventricular activation, ${ }^{14}$ and our $29^{\circ}$ phase delay suggests a $69 \mathrm{~ms}$ delay in contraction. In right bundle branch block Kastor $e t$ al showed that right ventricular outflow tract activation was delayed by $38 \mathrm{~ms},{ }^{15}$ and our phase delay of $23^{\circ}$ corresponds to $54 \mathrm{~ms}$. The increased delay of contraction after activation in bundle branch block may be caused by the delayed spread of activation through the ventricle.

Other studies have used the phase image to measure the timing of contraction, ${ }^{816-23}$ although most have looked at smaller numbers of patients. Their results are similar to ours, but differences are difficult to interpret because of the different ways of calculating phase. Frais et al and Botvinick et al for instance varied the frame length to achieve a better fit between the first Fourier harmonic and the actual activity-time curves. ${ }^{1920}$ This will decrease the rate dependence of phase but will itself alter values in a way which may not be identical in ventricles with different shaped activity-time curves. Their technique of looking for areas of earliest phase within each ventricle was able to show patterns of contraction in individual patients which were sometimes masked in our pooled data. The justification for pooling phase values is that it provides a reference range with which individual patients can be compared. One point of disagreement is that Frais et al found no increase in the variation of phase within the left ventricle in left bundle branch block, ${ }^{19}$ whereas we found a notable variation in indi- vidual patients, which was also reflected in the pooled data. Swiryn et al also found an increased variation, ${ }^{17}$ and, even when re-engagement of the Purkinje system distal to the site of block is allowed for, this is to be expected with a widened QRS complex.

\section{PROBLEMS}

Absolute values of phase are determined in part by the time at which the QRS complex is sensed, and changes in the shape of the complex may change this time. In paced patients for instance, sensing of the pacemaker artefact before the true QRS complex may introduce an apparent delay in contraction. The observed phase delays in paced patients are, however, too great to be explained entirely by this effect, and it cannot explain the variation within the ventricles. This problem can be avoided by choosing an electrocardiogram lead perpendicular to the vector of the pacing spike. Conversely, late sensing of the broadened QRS complex in left bundle branch block may suggest early contraction and a reduction in phase values. This effect is clearly small since high values are still observed.

Another problem is that the temporal resolution of the phase image is unknown, and since phase is determined by the shape of the whole activity-time curve rather than by any single parameter of its shape, the concept of temporal resolution does not have precise scientific meaning. The frame rate has less influence than might be expected since Fourier analysis is a curve fitting procedure, which allows extrapolation of curve values with a greater resolution than the sampling time. Sixteen frames per cycle is adequate to provide accurate activity-time curves, ${ }^{24}$ and increasing to 64 frames per cycle makes no apparent difference to phase values. ${ }^{16}$ The fact that phase differences as small as $3^{\circ}$ (between normal right and left ventricles) agree with other phase studies and with other measures of the timing of contraction ${ }^{1213}$ implies that temporal resolution is at least of this order.

A third problem is spatial interpretation of the phase image. Count variations seen by any pixel are due to motion of the ventricular wall both in front of and behind the column of blood seen by that pixel, and it is therefore imprecise to assign single areas of ventricular wall to any area of the phase image. This is complicated by the fact that attenuation of counts from the more distant inferior wall means that the phase image is less sensitive to motion of that wall. ${ }^{25}$ More information is obtained by acquiring a right anterior oblique first pass ventriculogram before the equilibrium study and generating from this a right anterior oblique phase image of the left ventricle. ${ }^{26} \mathrm{~A}$ combination of these two projections not only pinpoints any abnormality more precisely but also over- 
comes the problem of overlap between atria and ventricles in the left anterior oblique projection (even when modified by craniocaudal tilt).

\section{CONCLUSION}

Phase reflects the timing of ventricular contraction, and in normal ventricles the left ventricle contracts marginally before the right, with the right ventricular outflow tract being the last region to contract. In ventricles with delayed conduction the phase image indicates delayed contraction in a pattern that might be expected from a knowledge of the conducting system anatomy. In ventricles with areas of early depolarisation the phase image shows areas of early contraction.

The study was supported by a grant from the Sir Jules Thorn Charitable Trust.

\section{References}

1 Adam WE, Tarkowska A, Bitter F, Stauch M, Geffers H. Equilibrium (gated) radionuclide ventriculography. Cardiovasc Radiol 1979; 2: 161-73.

2 Geffers H, Adam WE, Bitter F, Seigel H, Kampman H. Data processing and functional imaging in radionuclide ventriculography. In: Brill AB, Price RR, eds. Information processing in medical imaging. Proceedings of Sth International Conference. Nashville: Biomedical Computing Technology Information Centre, 1977: 322-32.

3 Verba JW, Bornstein I, Alazraki NP, et al. Onset and progression of mechanical systole derived from gated radionuclide techniques and displayed in cine format [Abstract]. F Nucl Med 1979; 20: 625-6.

4 Bossuyt A, Deconinck F, Lepoudre R, Jonckheer M. The temporal Fourier transform applied to functional isotope imaging. In: Di Paolo R, Kahn E, eds. Information processing in medical imaging. Proceedings of the 6th international conference. Paris: INSERM, 1979; 88: 397408.

5 Pavel DG, Zimmer AM, Patterson VN. In vivo labelling of red blood cells with $99 \mathrm{~m}-\mathrm{Tc}$ : a new approach to blood pool visualization. F Nucl Med 1977; 18: 305-8.

6 Goris ML, Briandet PA, Huffer E. Automation and operator independent data processing of cardiac and pulmonary functions: role, methods and results. In: $\mathrm{Di}$ Paolo R, Kahn E, eds. Information processing in medical imaging. Proceedings of the 6th International Conference. Paris: INSERM, 1979; 88: 427-48.

7 Walton S, Yiannikas J, Jarritt PH, Brown NJG, Swanton RH, Ell PJ. Phasic abnormalities of left ventricular emptying in coronary artery disease. Br Heart $\mathcal{F} 1981 ; 46$ : 245-53.

8 Ell PJ, Walton S, Jarritt PH. Radionuclide ventricular function studies: correlation with $E C G$, echo, and $X$-ray data. The Hague: Martinus Nijhoff, 1982: 23-25, 132151.

9 Durrer D. Electrical aspects of human cardiac activity: a clinical-physiological approach to excitation and stimulation. Cardiovasc Res 1968; 2: 1-18.

10 Durrer D, Van Dam RT, Freud GE, Janse MJ, Meijler
FL, Arzbaecher RC. Total excitation of the isolated human heart. Circulation 1970; 41: 899-912.

11 Wyndham CRC, Meeran MK, Smith T, et al. Epicardial activation of the intact human heart without conduction defect. Circulation 1979; 59: 161-8.

12 Hotta $S$. The sequence of mechanical activation of the ventricle. Jpn Circ $\mathcal{F}$ 1967; 31: 1568-72.

13 Clayton PD, Bulawa WF, Klausner SC, Urie PM, Marshall HW, Warner HR. The characteristic sequence for the onset of contraction in the normal human heart left ventricle. Circulation 1979; 59: 671-9.

14 Wyndham CRC, Smith T, Meeran MK, Mammana R, Levitsky S, Rosen KM. Epicardial activation in patients with left bundle branch block. Circulation 1980; 61: 696-703.

15 Kastor JA, Goldreyer BN, Moore EN, Shelburne JC, Manchester $\mathrm{JH}$. Intraventricular conduction in man studied with an endocardial electrode catheter mapping technique. Circulation 1975; 51: 786-96.

16 Links JM, Douglass KH, Wagner HN Jr. Patterns of ventricular emptying by Fourier analysis of gated blood-pool studies. F Nucl Med 1980; 21: 978-82.

17 Swiryn S, Pavel D, Byrom E, et al. Sequential regional phase mapping of radionuclide gated biventriculograms in patients with left bundle branch block. Am Heart $\mathcal{f}$ 1981; 102: 1000-10.

18 Swiryn S, Pavel D, Byrom E, et al. Sequential regional phase mapping of radionuclide gated biventriculograms in patients with sustained ventricular tachycardia: close correlation with electrophysiologic characteristics. Am Heart f 1982; 103: 319-32.

19 Frais ME, Botvinick EH, Shosa DW, et al. Phase image characterization of ventricular contraction in left and right bundle branch block. Am $\mathcal{F}$ Cardiol 1982; 50: 95105.

20 Botvinick EH, Frais MA, Shosa DW, et al. An accurate means of detecting and characterizing abnormal patterns of ventricular activation by phase image analysis. $\mathbf{A m} \mathcal{F}$ Cardiol 1982; 50: 289-98.

21 Botvinick E, Dunn R, Frais M, et al. The phase image; its relationship to patterns of contraction and conduction. Circulation 1982; 65: 551-60.

22 Rosenbush SW, Ruggie N, Turner DA, et al. Sequence and timing of ventricular wall motion in patients with bundle branch block. Circulation 1982; 66: 1113-9.

23 Konishi T, Futagami Y, Hamada M, et al. Sequential phase analysis of ventricular contraction abnormalities in various conduction abnormalites; with special reference to WPW syndrome. $\mathcal{F p n ~ H e a r t ~} \mathcal{F}$ 1982; 23 (suppl 1): 169-71.

24 Hamilton GW, Williams DL, Caldwell JH. Frame-rate requirements for recording time-activity curves by radionuclide angiocardiography. In: Sorensen JA, ed. Nuclear cardiology: selected computer aspects. New York: Society of Nuclear Medicine, 1978: 75-83.

25 Underwood SR, Walton S, Laming PJ, Ell PJ, Emanuel RW, Swanton RH. Differential sensitivity of Fourier phase and amplitude images in the detection of anterior and inferior left ventricular wall motion [Abstract]. Nuclear Medicine Commurications 1983; 4: 135.

26 Walton S, Ell PJ, Jarritt PH, Swanton RH. Phase analysis of the first pass radionuclide angiocardiogram. Br Heart I 1982; 48: 441-8. 